\title{
AN ESSAY ON WAGES AND INCOME INEQUALITY IN THE U.S.
}

\author{
Diamando Afxentiou, New York Institute of Technology, U.S.A.
}

\author{
dx.doi.org/10.18374//JBR-21-1.3
}

\begin{abstract}
This essay looks at income inequality in the United States from a historical perspective. Income inequality is one of the most important economic problems of our time. Income inequality improved after the Great Depression and was stable until the 1970s when it started to increase again, surpassing the Great Depression era. This essay uses the U.S. Bureau of Labor Statistics Occupational Employment Statistics data from 2000 and 2010 to 2019. Results show that 57 percent of workers are in low-paying jobs earning 39 percent of the total compensation and 23 percent are in high-paying jobs earning 41 percent of the total compensation in 2019 , documenting that the unequal distribution of income still persists.
\end{abstract}

Keywords: Income inequality, wealth inequality, poverty, social safety net, occupation employment statistics data 